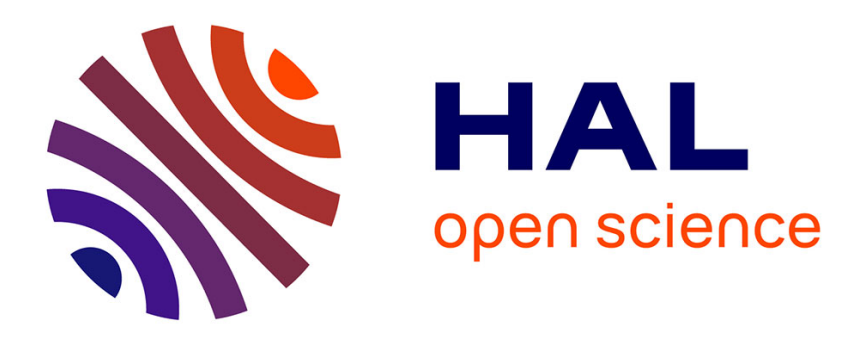

\title{
Building Process in Spinel Structure
}

X. Oudet

\section{- To cite this version:}

X. Oudet. Building Process in Spinel Structure. Journal de Physique IV Proceedings, 1997, 07 (C1), pp.C1-177-C1-178. 10.1051/jp4:1997164 . jpa-00255111

\section{HAL Id: jpa-00255111 https://hal.science/jpa-00255111}

Submitted on 1 Jan 1997

HAL is a multi-disciplinary open access archive for the deposit and dissemination of scientific research documents, whether they are published or not. The documents may come from teaching and research institutions in France or abroad, or from public or private research centers.
L'archive ouverte pluridisciplinaire HAL, est destinée au dépôt et à la diffusion de documents scientifiques de niveau recherche, publiés ou non, émanant des établissements d'enseignement et de recherche français ou étrangers, des laboratoires publics ou privés. 


\title{
Building Process in Spinel Structure
}

\author{
X. Oudet \\ Laboratoire Magnétisme et d'Optique de l'Université de Versailles, CNRS, 45 avenue des Etats-Unis, \\ 78035 Versailles, France
}

\begin{abstract}
The existence of inverse spinel is explained with a model of neutral atoms. The model supposes the existence of a trajectory for each electron keeping the most important aspect of the ionic approach. This allows to discuss the screening constant according to the coordination. The properties of each site are discussed in view of their Curie constants.
\end{abstract}

\section{INTRODUCTION}

Let us consider the $\mathrm{RM}_{2} \mathrm{O}_{4}$ spinels with $\mathrm{M}=\mathrm{Cr}, \mathrm{Mn}$ and $\mathrm{Fe}$ and $\mathrm{R}=\mathrm{Cr}, \mathrm{Mn}, \mathrm{Fe}, \mathrm{Co}$ and $\mathrm{Ni}$. When the $\mathrm{R}$ atom is in the tetrahedral $\mathrm{A}$ site the spinel is called normal and inverse if $R$ shares the octahedral $B$ site with one of the two $M$ atoms. The choice between normal and inverse $\mathrm{RM}_{2} \mathrm{O}_{4}$ spinel has been explained in terms of the ionic radius [1]. The possibility to describe ionic compounds with neutral atoms and corresponding radii has been underlined by Slater [2] and we have also shown the advantage of such a description [3]. The neutral state is also suggested from crystallo-chemical [4] and magnetic properties [5,6] showing that 3d electrons always stay on their atom whatever be their valenœe state. As a result we have still to understand the choice between normal and inverse spinel structure which is the purpose of this work. We will use the division of the $3 \mathrm{~d}$ shell into two subshells $3 \mathrm{~d}_{s_{2}}$ and $3 \mathrm{~d}_{52}$ according to Dirac's theory and as exhibited in magnetism $[5,6]$.

\section{THE TETRAHEDRAL SITE: NEUTRAL AND IONIC DESCRIPTION}

The tetrahedral arrangement is a good example to show the difference between the neutral and ionic descriptions. There is a lot of groups $\mathrm{AX}$, where the $\mathrm{A}$ atom is at the centre of a tetrahedron built with $\mathrm{X}$ atoms. It is the case of the two kinds of atoms for compounds with $\mathrm{ZnS}$ structure. It is also the case of radicals like $\mathrm{PO}_{4}, \mathrm{SO}_{4}, \mathrm{VO}_{4}$ and so on. All this tetrahedral groupings are covalent and this property appears to be characteristic of the tetrahedral site.

This property can be understood with electrons gravitaing along a trajectory. We have already discussed about arguments supporting the trajectory [3] and recently shown those from Dirac's theory $[7,8]$. The electron is supposed to be a fluid mass exchanging matter with the field. Dirac's equation appears to be the differential exuation governing these exchanges and the wave function to be the mechanical action leading the electron along its trajectory. Let us then consider a regular tetrahedral site. The three straight lines $\delta$ crossing two opposite edges in their middle make a system of orthogonal axes. With a neutral $\mathrm{A}$ atom of metal at the centre of the site, each valence electrons will gravitate in the vicinity of a plane containing two $\delta$ straight lines in such a way that at least one of the outermost valenœe electron of the $X$ atoms can be attracted by the pasitive kernel of the $\mathrm{A}$ atom. This is the covalent contribution to the bonds between $\mathrm{A}$ and $\mathrm{X}$ atoms. Let us restrict the discussion to oxygen tetrahedron. When one valence electron of the atom $A$ passes in the vicinity of an oxygen atom it will be attracted by its kernel through the $2 p$ hole; it is the valence contribution to the bonds between $A$ and $O$ atoms. Now this valence electron can gravitate between $2 p$ holes of two oxygen atoms increasing the valence binding. These are the characteristics of the bonds in the tetrahedral site with neutral atoms. This approach has the advantage to distinguish the valence bonds from the covalent contribution close to the notion of coordination. We can extend the discussion to the octahedral site occupation of chromium.

\section{THE OCTAHEDRAL SITE AND THE ELECTRONIC STRUCTURE OF CHROMIUM}

Chromium is known to occupy the octahedral site of the $\mathrm{RCr}_{2} \mathrm{O}_{4}$ spinels. Let us consider the electronic configuration of the 3d shell in Dirac's model. The corresponding trajectories are close to that of Bohr Sommerfeld's model. The main difference is that there is one unit of quantification used for the own rotation of the electron. This unit gives rise to a rotation with an angular momentum $1 / 2 \mathrm{~h}$ in the projection 
plane $x, y$ that we will call the equatorial plane. The gravitation plane exhibits an angle $\theta$ with the equatorial plane different from zero. This angle is bigger as the smaller the projection of the total angular momentum.

Now the $3 \mathrm{~d}$ shell is divided into $3 \mathrm{~d}_{32}$ subshell with four quantum states and $3 \mathrm{~d}_{52}$ subshell with six. Thus the chromium with four $3 \mathrm{~d}$ electrons, appears as the element for which the $3 \mathrm{~d}_{32}$ subshell has its four quantum states oocupied without any electron on the $3 \mathrm{~d}_{5 / 2}$ subshell [5]. This situation gives to chromium a very particular property. Indeed between the two subshells the orientation of the gravitation planes are somewhat different. In the $3 \mathrm{~d}_{32}$ subshell there is no quantum states with electron gravitating in the vicinity of the equatorial plane; on the contrary the first cocaupied quantum state of the $3 \mathrm{~d}_{5 / 2}$ subshell is close to this plane. As a result for the chromium in all directions close to the equatorial plane the screening constant is smaller than those corresponding to occupied quantum states. This situation favour the square planar coordination. Let us now consider the azimutal direction perpendicular to the equatorial plane. In the $3 \mathrm{~d}_{32}$ subshell the electron cannot be so close of it as in the $3 d_{5 / 2}$ subshell. As a result in chromium in the vicinity of the azimutal direction the screening constant is also small. This leads to the coordination two in this direction that is with the square coordination to the octahedral coordination.

Let us now consider manganese, the additional electron cocupies one of the most equatorial state on $3 \mathrm{~d}_{52}$. This increases the screening constant in the vicinity of the equatorial plane and the octahedral coordination is not so strong as in chromium. In the tetrahedral site this $3 \mathrm{~d}_{3 / 2}$ electron will gravitate between the oxygen atoms as already explained. On the other hand in the tetrahedral coordination with four oxygen atoms in place of six the repulsive interactions between these oxygen atoms are lower than in the octahedral site. This fact allows shorter distances and stronger attractions and the tetrahedral site is more covalent than the octahedral site. We suppose that it is for these different aspects of sreening constants and coordination that manganese is more stable in the tetrahedral site and chromium in the octahedral one. Now the increase of the charge of the nucleus allows, for similar sreening constant, higher coordination. Thus $\mathrm{RM}_{2} \mathrm{O}_{4}$ with $\mathrm{R}$ having higher change of the nucleus than $M$ must be inverse spinel.

\section{CRYSTALLOGRAPHIC SITE AND CURIE CONSTANT}

With a more covalent tetrahedral site one can suppose more electrons with a quenched paramagnetic contribution in this site than in the cotahedral one as a result a lower Curie constant. In other words these remarks favour for the same element, higher valence state in tetrahedral than in octahedral site. The calculation of the Curie constant (figure 1) according to [5] is in agreement with these sites preference properties. Indeed with normal $\mathrm{RCr}_{2} \mathrm{O}_{4}$ spinels the Curie constant value is explained with just one $\mathrm{C}(\mathrm{Cr})$ contribution but two different $\mathrm{C}(\mathrm{M})$ contributions with the inverse $\mathrm{RM}_{2} \mathrm{O}_{4}$. In this case the lower $\mathrm{C}(\mathrm{M})$ values can be supposed to be that of the tetrahedral site. It is one of the advantages of this approach to be able to propose different values of the Curie constant for the same ion, that one has to compare the spin only value which leads often to values not in agreement with the experiment.

\begin{tabular}{|c|c|c|c|c|c|c|c|c|c|}
\hline & & & & & & this work & exp. & spin only & ref. \\
\hline $\mathrm{Fe}_{3} \mathrm{O}_{4}$ & & & I & & $\| F e_{\mu}$ & 14.02 & 14.2 & 11.76 & 9 \\
\hline $\mathrm{CoFe}_{2} \mathrm{O}_{4}$ & & & & $\mathrm{HCO}_{n}$ & $I^{\prime \prime}$ & 13.95 & 13.9 & 10.64 & 9 \\
\hline $\mathrm{NiFe}_{2} \mathrm{O}_{4}$ & & $\mid N i_{n}$ & 1 & & I & 9.54 & 9.76 & 9.76 & 9 \\
\hline $\mathrm{MnCr}_{2} \mathrm{O}_{4}$ & & $\|$ & & $M n_{I I}$ & & 8.59 & 8.34 & 11.76 & 10 \\
\hline $\mathrm{CoCr}_{2} \mathrm{O}_{4}$ & & II & $I C o_{I I}$ & & & 7.46 & 7.48 & 5.64 & 10 \\
\hline $\mathrm{NiCr}_{2} \mathrm{O}_{4}$ & & $\| \mid N i_{u}$ & & & & 6.51 & 6.60 & 4.76 & 10 \\
\hline $\mathrm{CrMn}_{2} \mathrm{O}_{4}$ & & $\| \mathrm{Cr}_{I I}$ & 1 & & & 7.41 & 7.16 & 9.76 & 11 \\
\hline $\mathrm{NiMn}_{2} \mathrm{O}_{4}$ & I & $\| N i_{n I}$ & & & & 5.73 & 6.00 & 7.00 & 12 \\
\hline \multirow[t]{3}{*}{$\mathrm{LiMn}_{2} \mathrm{O}_{4}$} & 1 & 1 & & & & 3.56 & 3.34 & 4.88 & 13 \\
\hline & I & I & I & I & I & & & & \\
\hline & 1.39 & 2.17 & 3.12 & 4.25 & $5 . \overline{45}$ & & & & \\
\hline
\end{tabular}

Figure 1 Calculation of the Curie constant of $\mathrm{RM}_{2} \mathrm{O}_{4}$ spinels and comparison to the experimental and spin only values in Kemu/gat unit. The calculated value is the sum of the of the numbers at the bottom of the corresponding dash.

\section{References}

[1] Barth T.F.W. and Posnjak E.,J. Washington Acad Sci., 21 (1931) 255-8, and Z. Kristallogr., 82, (1932) $325-341$.

[2] Slater J. C., J. Chem. Phys., 41 (1964) 3199 -3204.

[3] Oudet X, Ann. Fond Louis de Brolgie, 17 (1992) 315-345.

[4] Oudet X, Ann de Chimie, France, 8 (1983) 483-507.

[5] Oudet X.and Lochak G., J. Mag Mag Mat65 (1987) 99-122.

[6] Oudet X, J. Mag Mag Mat, 98 (1991) 298-306 and 307-332.

[7] Oudet X, Ann. Fond Louis de Brolgie, 20 (1995) 473-490.

[8] Oudet X, J. Appl. Phys., 79(1996) 5416-5418.

[9] Fallot M and Maroni P., J. Phys. Rad, 12 (1951) 256-257.

[10] McGuire T.R,Howard L.N. and Smart J.S., Ceramic Age 60 (1952) 22-24.

[11] Boucher B, Buhl R. and Perrin M., J. Phys. Chem. Solids, 32 (1971) 1471-1488.

[12] Boucher B, Buhl R and Perrin M., J. Phys. Chem. Solids, 31 (1970) 363-383.

[13] Baltzer P.K. and Lopatain E., Proc. 1.C.M. Nottingham, 564-567. 